\title{
Fabricate and Characterization by lonotropic Gelation Technology of the MicroBeads Loaded with Dicyclomine Hydrochloride for Gastroretentive Drug Delivery System
}

\author{
Kaushlendra Pratap Singh*, Sachin Kumar \\ Department of Pharmaceutics, NKBR College of Pharmacy and Research Center, Meerut, Uttar Pradesh, INDIA.
}

\begin{abstract}
Objectives: The principal objective of this research is to fabricate, characterize and in vitro evaluation of floating gastroretentive Dicyclomine Hydrochloride beads. Methods: In this study, lonotropic gelation technology was used to float gastro retentive Dicyclomine Hydrochloride beads. Subsequently, the floating properties, entrapment efficiency, in vitro release of beads were all determined during the characterization process. Results: The results showed concluded that formulation B11 have shown higher total floating time and lesser floating lag time values and a better drug release profile. Conclusion: Six formulations B3, B6, B9, B10, B11, and B12, met all of the requirements and features necessary for a successful floating formulation. For the preparations, all of the evaluation tests were completed. With changes in the ratio of sodium alginate and Hydroxypropyl Methylcellulose and the number of effervescent agents in the formula-
\end{abstract}

tions, the formulations' drug release pattern and floating capabilities were shown to be varied. The experiment and the results reveal that Dicyclomine Hydrochloride floating beads enhance stomach residence and bioavailability while decreasing the dosage and dosage interval.

Key words: MicroBeads, Gastroretentive Drug Delivery System, Dicyclomine Hydrochloride, Ionotropic gelation method, Bioavailability enhancement.

Correspondence

Kaushlendra Pratap Singh,

Department of Pharmaceutics, NKBR College of Pharmacy and Research Center, Meerut-250004, Uttar Pradesh, INDIA.

Email id: kkaushlender15@gmail.com

DOI: $10.5530 /$ /ijpi.2021.3.50

\section{INTRODUCTION}

The drug delivery system's primary purpose is to reach the drug's required blood or tissue concentration, which is non-toxic and long-lasting therapeutic. ${ }^{1}$ An optimum dosage scheme in the treatment of drugs for any condition is the one that achieves the target plasma-(or site-ofaction) therapeutic concentration instantly and keeps this drug constant during the treatment. ${ }^{2}$ The traditional approach for distributing drugs, which is accomplished and maintains therapeutic concentration, is only needed many times a day in therapeutic efficacy. ${ }^{3}$ In the gastrointestinal tract (GIT), medications with a limited absorption site will have a low and reduced absorption level. Gastric retentive drug delivery systems help in providing an advantage in increasing the period for stomach emptying. ${ }^{4}$ Gastro retentive drug delivery methods enhance the bioavailability of medications since they are kept in the stomach for the given period. To increase the duration that the medication is in the gastrointestinal (GI) tract, it does so in a region of the GI tract that would enhance the absorption of the medication when it is in solution and ready for absorption. ${ }^{5}$ The concept is that medication delivery happens when the drug's density is low. By holding the medicine in the stomach for a longer duration, bioavailability is improved, drug waste is minimized, and insoluble medicines become more soluble. ${ }^{6}$ While it may also be used for localized medication administration to the stomach and proximal small intestines, it has other practical applications. The bioavailability of novel pharmaceuticals with better therapeutic potential and significant benefits for patients is possible because of gastric retention. ${ }^{7}$ Dicyclomine Hydrochloride is a synthetic tertiary amine antispasmodic that works by blocking muscarinic receptors. Absorption and Distribution: Dicyclomine
Hydrochloride is rapidly absorbed in the gastrointestinal tract. ${ }^{8}$ The relative oral bioavailability of the medication following a single oral or intramuscular dosage is approximately $67 \%$ of the intramuscular injection. ${ }^{9}$ It is readily soluble in chloroform and ethanol and is also highly soluble in water. It is poorly soluble in ether. Approximately $80 \%$ of the dosage is excreted in the urine, with the remaining $10 \%$ excreted in faeces. Dicyclomine is used to treat the motility of the intestines and the symptoms of bowel irritation (also known as the spastic colon).$^{10}$ It alleviates muscular spasms, including cramping in the gastrointestinal system, by suppressing acetylcholine activation on cholinergic (or muscarin) receptors on muscle cell surfaces. ${ }^{11-13}$

\section{MATERIALS AND METHODS}

\section{Materials}

Penta Biotech Pvt. Ltd., Haridwar, provided Dicyclomine Hydrochloride as a complimentary sample. All chemicals such as $\mathrm{CH}_{3} \mathrm{COOH}$, HPMC, $\mathrm{NaHCO}_{3}, \mathrm{CaCl}_{2}$ and Sodium Alginate used in this research are of analytical grade.

\section{Methods}

The Ionotropic gelation process was used to make calcium alginate beads. Different formulations of Dicyclomine Hydrochloride alginate beads were made using this approach. In $20 \mathrm{~mL}$ of water, $120 \mathrm{mg}$ of Dicyclomine Hydrochloride was distributed. The resultant dispersion was gently mixed with a mixture comprising sodium alginate, HPMC, and sodium bicarbonate at various concentrations. The resultant 
solution was injected into a $3 \% \mathrm{w} / \mathrm{v} \mathrm{CaCl}_{2}, 10 \% \mathrm{v} / \mathrm{v} \mathrm{CH}_{3} \mathrm{COOH}$ using a $26 \mathrm{G}$ syringe needle. To increase the strength of the beads, they were agitated for $10 \mathrm{~min}$ using a magnetic stirrer at $50 \mathrm{rpm}$, and the reaction to create gas inside the alginate beads were allowed to finish. After filtering and rinsing the produced beads with distilled water, they were ready to be used. The beads are then dried after they have been cleaned.

\section{Characterization and evaluation of Dicyclomine Hydrochloride alginate beads}

Identification of drug: Identifications of the drug are commonly carried out using the sample was subjected to infrared (IR) spectroscopy.

Melting point: A capillary method and digital melting point instrument were used to calculate the melting point of Dicyclomine Hydrochloride (Labindia).

Loss on Drying (LOD): A precise weight of $1.0 \mathrm{~g}$ of the medication was used. For $4 \mathrm{hrs}$, the substance is kept inside the oven at $105^{\circ} \mathrm{C}$, and for $4 \mathrm{hrs}$, the substance is weighed again.

Analysis of Solubility in Different Solvent: The compound Dicyclomine Hydrochloride on dissolving in various solvents has been found to dissolve quickly in the maximum solvent and exhibits a good solubility. The assessment of a drug's solubility is critical since the drug's initial step in the body is to enter the solution. Therefore, the equilibrium technique is used to determine solubility in different solvents.

$p H$ : This indicates the acidic or basic properties of the medication. Dissolve 0.5 grams in $50 \mathrm{~mL}$ water. A digital $\mathrm{pH}$ meter was used to determine the $\mathrm{pH}$.

Distribution Coefficient $\left(\boldsymbol{P}_{\text {o/W }}\right): 40 \mathrm{~mL}$ of octanol+water is taken in an equal ratio in a $100 \mathrm{~mL}$ flask, and $20 \mathrm{mg}$ of the accurately weighed drug is added to it. After this, it is kept on a rotary flask shaker to shake continuously for $24 \mathrm{hrs}$. A separating funnel then separates the two layers. After continuous dilution, the drug is checked on a UV Spectrophotometer at $215 \mathrm{~nm}$ against blank solution as a reagent. The distribution coefficient is determined using an appropriate formula which is as follow:

$$
\mathrm{Po} / \mathrm{w}=\frac{[\mathrm{A}]_{\mathrm{org}}}{[\mathrm{A}]_{\mathrm{aq}}}
$$

Where: [A] represents the concentration of solute, "org" refers to the organic, "aq" aqueous phases. ${ }^{14}$ Drug + Excipient Interaction Study: A FTIR investigation was conducted to look for any potential drug-polymer interactions. In comparison with the identical mixtures, pure drug and individual pure polymer peaks and no significant changes were found in the band as an indicator of the interaction.

\section{Analytical Process Development}

\section{$\lambda_{\max }$ detection of Dicyclomine Hydrochloride}

The wavelength of Dicyclomine Hydrochloride is measured through spectrophotometric analysis. It is scanned in the presence of a blank sample at 200 to $400 \mathrm{~nm}$ wavelength in a UV spectrophotometer. The $\lambda_{\max }$ was determined to be $215 \mathrm{~nm}$, which was utilized to determine Dicyclomine Hydrochloride in test materials by spectrophotometry.

\section{Preparation of Standard Curve}

The standard curve is a fast and accurate method for measuring Dicyclomine Hydrochloride, in which the drug is, measured spectrophotometrically at a fixed technique at the defined $\lambda_{\max }$. Different standard samples are prepared using distilled water, and their $\mathrm{pH}$ is maintained to be 1.2 with the help of $0.1 \mathrm{~N} \mathrm{HCl}$. A set of standard samples were made using distilled water and adjust $\mathrm{pH} 1.2$, with $0.1 \mathrm{~N} \mathrm{HCl}$.
Dicyclomine Hydrochloride in Distilled Water: The wavelength of Dicyclomine Hydrochloride is measured through spectrophotometric analysis. It is scanned in the presence of a blank sample at 200 to $400 \mathrm{~nm}$ wavelength in a UV spectrophotometer.

\section{Evaluation of Formulations}

Determination of percentage yield: The following calculation was used to compute the percentage yield for the formulated beads.

$$
\text { Yield } \%=\frac{\text { Actual weight }}{\text { Theoretical weight }} \times 100
$$

Floating Properties: In 900mL of $0.1 \mathrm{~N} \mathrm{HCl}$ medium, 50mg beads were put. In a dissolving vessel [USP Type II dissolution tester], the floating capabilities of beads were tested. The paddle rotation speed was measured at 50 rotations per minute. The temperature was kept at $370^{\circ} \mathrm{C}$. Visual observation was used to determine the samples' floating properties. ${ }^{15}$

$$
\frac{\text { The actual amount of drug (AQ) }}{\text { Theoretical amount of drug (TQ) }} \times 100
$$

Determination of Entrapment efficiency $100 \mathrm{~mL}$ of $0.1 \mathrm{~N} \mathrm{HCl}$ was used to create the proportion, $50 \mathrm{~mL} 0.1 \mathrm{~N} \mathrm{HCl}$ was added to an adequately weighed amount of about $50 \mathrm{mg}$ beads, and the mixture was agitated in a graduated flask. The mixture was subsequently filtered, and a UV spectroscopy test was performed at $215 \mathrm{~nm}$. In order to calculate the entrapment efficiency, an equation was utilized:

\section{Determination of in -vitro Dissolution Study}

A USP-II type (paddle type) dissolution device was used for the investigation. Dissolution was checked at $50 \mathrm{rpm}$ in $900 \mathrm{~mL} 0.1(\mathrm{~N})$ Hydrochloride. At certain times, a $5 \mathrm{~mL}$ sample was collected, and the volume of the dissolving medium maintained when an equal amount of dissolution media was added. The absorbance of the sample was obtained with a good calibration curve to determine the dilution and corresponding concentration.

\section{RESULTS}

\section{Characterization of Dicyclomine Hydrochloride alginate beads}

It is vital to identify some essential physical and chemical qualities before the development of any formulation. Therefore, all results such as analytical method, analysis of melting point, analysis of Loss on drying, Solubility Analysis, $\mathrm{pH}$ Analysis, analysis of distribution coefficient, IR spectroscopy, and compatibility study of drug excipient are shown in Table 1 and Identification of Dicyclomine Hydrochloride using FTIR are shown in Figure 1.

\section{Evaluation of Dicyclomine Floating Hydrochloride Beads}

Nine Dicyclomine floating Hydrochloride bead formulations were produced utilizing sodium alginate, $\mathrm{HPMC}, \mathrm{NaHCO}_{3}, \mathrm{CaCl}_{2}$, and $\mathrm{CH}_{3} \mathrm{COOH}$. The ionic gelation process is used to make the beads. All of the formulations were tested and results of evaluation are as follow:

Per cent yield and per cent floating: Percent yield is the percent ratio of actual yield to the theoretical yield. Percentage of yield and floating about various beads formulations are shown in Table 2 .

Entrapment efficiency: At the curing time period there is an evolution of a dense matrix structure as it diminishes the loss of drug and hence increases the level of alginate concentration. The results of $\%$ entrapment of formulations are shown in Table 3. 
Table 1: Results of the Characterization of Dicyclomine Hydrochloride alginate beads. ${ }^{1}$

\begin{tabular}{|c|c|c|}
\hline $\begin{array}{l}\text { Analyzed } \\
\text { property }\end{array}$ & Observation & Inference \\
\hline Colour & White & --- \\
\hline $\begin{array}{l}\text { Analytical } \\
\text { method }\end{array}$ & $\begin{array}{l}\text { Spectrophotometry at } 215 \\
\mathrm{~nm} \text { in the ultraviolet-visible } \\
\text { range }\end{array}$ & $\begin{array}{c}\text { Beer-Lambert law } \\
\text { followed good linearity } \\
\mathrm{R}^{2}=0.99\end{array}$ \\
\hline $\begin{array}{c}\text { Analysis of } \\
\text { Melting point }\end{array}$ & $172.5^{\circ} \mathrm{C}$ & Thermolabile \\
\hline $\begin{array}{l}\text { Analysis of Loss } \\
\text { on drying }\end{array}$ & $>0.5 \%$ & Within a specific range \\
\hline $\begin{array}{l}\text { Solubility } \\
\text { Analysis }\end{array}$ & $\begin{array}{c}\text { In Water: } 38.232 \\
\text { In } 0.1 \mathrm{~N} \mathrm{HCl:12.158} \\
\text { In Chloroform: } 34.365\end{array}$ & $\begin{array}{c}\text { Freely soluble in water } \\
\text { and chloroform, In } 0.1 \mathrm{~N} \\
\mathrm{HCl} \text {, it is just slightly } \\
\text { soluble. }\end{array}$ \\
\hline pH Analysis & 5.1 & Faintly acidic \\
\hline $\begin{array}{l}\text { Analysis of } \\
\text { Distribution } \\
\text { coefficient }\end{array}$ & 0.83 & Hydrophilic in nature \\
\hline IR spectroscopy & $\begin{array}{l}\text { The significant peaks of the } \\
\text { drug are shown }\end{array}$ & $\begin{array}{l}\text { In comparison to a } \\
\text { monograph }\end{array}$ \\
\hline $\begin{array}{l}\text { Compatibility } \\
\text { study of drug } \\
\text { excipient }\end{array}$ & $\begin{array}{l}\text { The significant peaks of the } \\
\text { drug are displayed }\end{array}$ & $\begin{array}{l}\text { There have been no major } \\
\text { alterations to the peaks. }\end{array}$ \\
\hline
\end{tabular}

1 Results of the Characterization of Dicyclomine hydrochloride alginate beads are shown in the table.

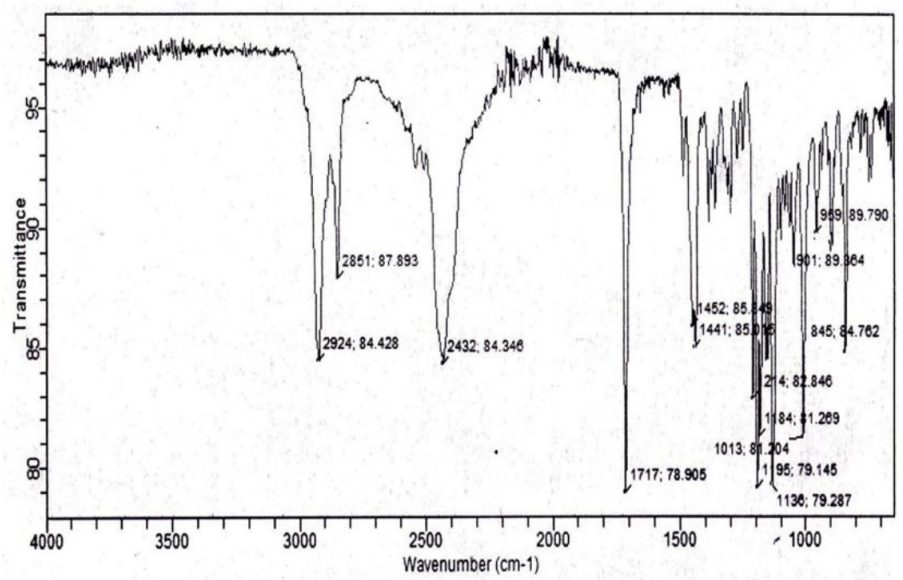

Figure 1: Identification of Dicyclomine Hydrochloride using FTIR.

Table 2: \% yield and \% floating B2-B12. ${ }^{1}$

\begin{tabular}{ccc}
\hline Formulations & \% Yield & \% Floating after 8 hrs \\
\hline B2 & 79.5032 & 0 \\
B3 & 84.09090 & 42 \\
B5 & 75.63 & 0 \\
B6 & 82.57575 & 42 \\
B8 & 79.70666 & 0 \\
B9 & 83.33332 & 61 \\
B10 & 81.81817 & 61 \\
B11 & 75.75757 & 82 \\
B12 & 81.06060 & 82 \\
\hline
\end{tabular}

1 Formulation B3 showed the highest \% yield.

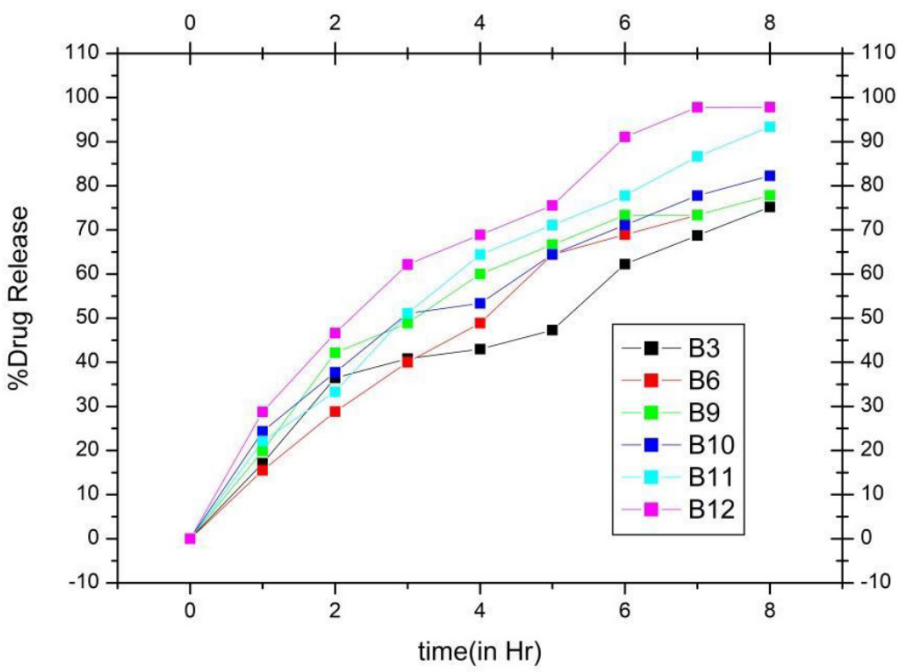

Figure 2: Cumulative \% drug release B3-B12.

Table 3: \% Drug entrapment B3-B12. ${ }^{1}$

\begin{tabular}{cl}
\hline Formulation & $\%$ DEE \\
\hline B3 & 92.61 \\
B6 & 89.53 \\
B9 & 96.13 \\
B10 & 88.65 \\
B11 & 95.03 \\
B12 & 96.79 \\
\hline
\end{tabular}

1 Formulation B12 showed the highest \% Drug entrapment.

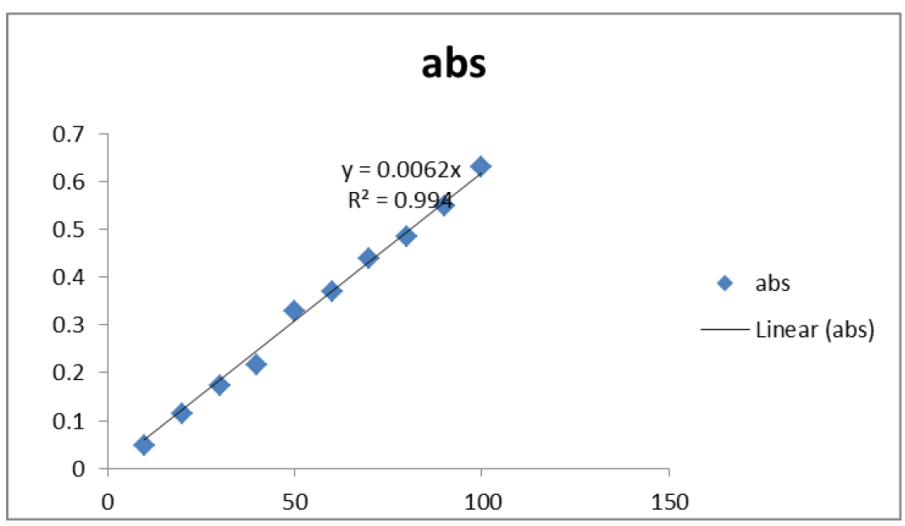

Figure 3: Calibration curve of the drug in distilled water.

\section{Studies of in vitro release of drugs}

The results of in vitro release of drugs of formulations shown in Figure 3. As the concentration of $\mathrm{CaCl}_{2}$ increased from $1 \%$ to $2 \%$, there was a significant reduction in the Dicyclomine Hydrochloride cumulative release percentage.

\section{DISCUSSION}

Characterization of drug provides a framework for a large number of events and techniques in the formulation and development process. This first stage of development is referred to as a pre-formulation study. These 
investigations should concentrate on the physicochemical features of the novel molecule that can alter the performance of drugs and create an effective dosage form. We conducted the following preformulation investigations. $^{16}$

After characterization the colour of compound is white and when measured with a UV spectrophotometer it shows a peak at $215 \mathrm{~nm}$.

Loss on drawing was used to calculate the moisture content in which it falls within a range which is $>0.5 \%$.

In solubility analysis it show good solubility in water and chloroform and in $0.1 \mathrm{~N} \mathrm{HCl}$ it is slightly soluble.

All of the formulations had a percentage yield ranging from $75 \%$ to $95 \%$, with the formulation B1 in Table 1 having the highest percentage yield (95.94\%). There is an increase in the yield because of increase in concentration $\mathrm{CaCl}_{2}$ by $1 \%$ that is from 1 to 2 . A further increase to $2 \%$ of the cross-link agent concentration had a negligible effect on production.

The formulations were studied for lag time and percentage of floating. There was no lag floating time shown in any of the formulations. ${ }^{17}$ The formulation B1, B2, B4, B5, B7, B8 does not show any buoyancy, and the floating percentage in other formulation B3, B6, B9, B10, B11 and B12 showed good buoyancy that varies from $40-80 \%$. The formulation had a more significant duration and percentage of floating ( $8 \mathrm{hrs})$; hence it was chosen for future studies. ${ }^{18}$

The mean melting point was calculated as $173^{\circ} \mathrm{C}$. Loss on drying measured less than $0.5 \%$. The $\mathrm{pH}$ value of the drug has been determined to be 5.1. Beads that are filled with drugs are very important for drug delivery and still there is less research that is done to analyze drug-bead interactions and also relates with the resultant product and their behavior. After research it is found about some important drug-bead physiochemical parameters. These parameters are factors that affect binding and also later drug release phenomena that challenges the conditions like mimicking the clinic as well as body. In drug excipient interaction show significant peak at 1117 and 1196 having no incompatibility with ingredients.

The absorbance of various medication concentrations and their related concentrations are displayed. Figure 3 shows the standard matching curve obtained using linear regression analysis and the mathematical equation that represents the curve. The percentage of drug entrapment in alginate beads is determined for several formulations of alginate beads. Due to the rise in percentage of $\mathrm{CaCl}_{2}$ that is from $1 \%$ to $2 \%$ because of this there is a rise in percentage of entrapment of drug from (B10) $88 \%$ to (B11) 95\%. In addition, the entrapment efficiency and drug content were investigated, with good results ranging from 88.66 to $96.80 \%$.

Drug releases from the prepared beads were examined by using a paddle (USP II) device. The release of the drug was determined using UV absorption spectroscopy at a wavelength of $215 \mathrm{~nm}$. The in vitro release experiment was conducted using $0.1 \mathrm{~N} \mathrm{HCl}$. After eight hours, $97.8 \%$ of the drug was released. All of the formulations studied in the dissolving investigation showed consistent Dicyclomine Hydrochloride release within an 8 -hr timeframe. ${ }^{19}$ Figure 2 showed the results of Cumulative \% drug release B3-B12. The formulation B12, which showed 93\% cumulative drug release over $8 \mathrm{hrs}$, was the best.

\section{CONCLUSION}

In such a study, floating alginate beads of Dicyclomine Hydrochloride have been employed for the production of sodium alginate, HPMC E5LV, sodium hydro-carbonate, calcium chloride and glacial acetic acid. Six formulations, B3, B6, B9, B10, B11, and B12, met all of the requirements and features necessary for a successful floating formulation. For the preparations, all of the evaluation tests were completed. With changes in the ratio of sodium alginate and HPMC and the amount of effervescent agents in the formulations, the formulations' drug release pattern and floating capabilities were shown to be varied. Furthermore, Dicyclomine Hydrochloride has analyzed in vitro from the produced formulations by plotting the cumulative percentage of released drugs vs time. Thus it can be concluded that formulation B11 have shown higher total floating time and lesser floating lag time values as well as better drug release profile. This project attempts to justify the possibility of formulating a floating dosage form of Dicyclomine Hydrochloride employing the rational combination of polymers and excipient. The experiment and the results reveal that Dicyclomine Hydrochloride floating beads enhance stomach residence and bioavailability while decreasing the dosage and dosage interval.

\section{ACKNOWLEDGEMENT}

Special thanks to higher authorities of the Department of Pharmaceutics, NKBR College of Pharmacy and Research Center, Meerut, Uttar Pradesh, India, to help and provide moral support for this research work.

\section{CONFLICT OF INTEREST}

The authors declare no conflict of interest.

\section{ABBREVIATIONS}

FTIR: Fourier-transform infrared spectroscopy; PVP: Polyvinylpyrrolidone; HPMC: Hydroxypropyl methylcellulose.

\section{REFERENCES}

1. Borase CB. Floating systems for oral controlled release drug delivery. Int J Appl Pharm. 2012;4(2):1-13.

2. Brahmankar DM, Jaiswal SB. Biopharmaceutics and Pharmacokinetics A Treatise. Vallabh prakashan. Delhi. $1^{\text {st }}$ ed; 2005. p. 335-7.

3. Nasa P, Mahant S, De S. Floating systems: A Novel approach towards gastroretentive drug delivery systems. Int J Pharm Pharm Sci. 2000;2(3):2-7.

4. Kumar M. FLOATING DRUG DELIVERY SYSTEM: A INNOVATIVE APPROACH. J Drug Delivery Ther;2(6). doi: 10.22270/jddt.v2i6.315.

5. Dighe A, Choudhary NH, Thorat MS, Prasad RV, Manoj S. Floating Drug Delivery System: A Novel Approach towards Gastro retention. Int J Pharm Chem Sci. 2012;1(3):779-3

6. Abdul S, Mallikarjun KB, Hamed M. SGada S. Gastro Retentive Drug Deliv Syst Rev Sch Res J. 2011;3(1):121-37.

7. Karen HD, Anand IS, Patel CN. Gastroretentive approaches: A part of Novel drug delivery system. Int J Drug Dev Res. 2012;3(1):29-42.

8. Khirwadkar P, Dashora K. Gastroretentive dosage forms: current developments in Novel system design and evaluation. Am J PharmTech Res. 2011;1(3):57-87.

9. Rao GU, Murari P. Buoyant sustained release drug delivery systems current potentials advancements and role of polymers: a review. Int. Commun Phys. 2012;02(1):1-7.

10. Kumar S, Jamil F, Rajput M, Sharma S. Gastro retentive drug delivery system: features and facts. Int J Pharm. 2012;3(1):125-36.

11. Raymond CR, Paul JS, Marian EQ. Handbook of Pharmaceutical Excipients. Pharmaceutical Press An imprint of RPS Publishing London. 6 $6^{\text {th }}$ ed. 2009. $P ; 89(326), 622: 629$.

12. Bhatt $P$, Singh $S$, Kumar Sharma S, Rabiu S. Development and characterization of fast dissolving buccal strip of frovatriptan succinate Monoydrate for buccal delivery. Int J Pharm Investig. 2021;11(1):69-75. doi: 10.5530/ijpi.2021.1.13.

13. MurataY, Sasaki N, Miyamoto E, Kawashima SY. Use of floating alginate gel beads for stomach-specific drug delivery. Eur J Pharm Biopharm. 2000;50(2):221-6. doi: 10.1016/s0939-6411(00)00110-7, PMID 10962231.

14. Joseph NJ, Lakshmi S, Jayakrishnan A. A floating-type oral dosage form for piroxicam based on hollow polycarbonate microspheres: in vitro and in vivo evaluation in rabbits. J Control Release. 2002;79(1-3):71-9. doi: 10.1016/s01683659(01)00507-7, PMID 11853919

15. Streubel A, Siepmann J, Bodmeier R. Floating matrix tablets based on low density foam powder: effects of formulation and processing parameters on drug release. Eur J Pharm Sci. 2003;18(1):37-45. doi: 10.1016/s0928-0987(02)00223-3, PMID 12554071.

16. Sriamornsak P, Thirawong N, Puttipipatkhachorn S. Emulsion gel beads of calcium pectinate capable of floating on the gastric fluid: effect of some 
additives, hardening agent or coating on release behavior of metronidazole. Eur J Pharm Sci. 2005;24(4):363-73. doi: 10.1016/j.ejps.2004.12.004, PMID 15734303.

17. Ferreira Almeida PF, Almeida AJ. Cross-linked alginate-gelatine beads: a new matrix for controlled release of pindolol. J Control Release. 2004;97(3):431-9. doi: 10.1016/j.jconrel.2004.03.015, PMID 15212875.

18. Chavanpatil M, Jain P, Chaudhari S, Shear R, Vavia P. Development of sustained release gastroretentive drug delivery system for ofloxacin: in vitro and in vivo evaluation. Int J Pharm. 2005;304(1-2):178-84. doi: 10.1016/j.ijpharm.2005.08.009, PMID 16198522.

19. Bhanu PN, et al. Development of microballoons and immediate release granules of pantoprazole sodium for gastro retentive drug delivery. Int J Ph Develop Tech. 2013;3(1):41-51.

Article History: Submission Date : 07-06-2021; Revised Date : 14-07-2021; Acceptance Date : 26-08-2021.

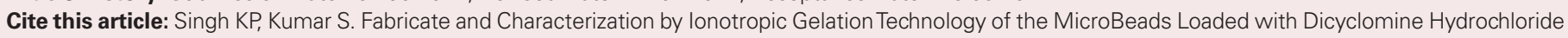
for Gastroretentive Drug Delivery System. Int. J. Pharm. Investigation. 2021;11(3):283-7. 